\title{
ANALYSIS AND DESIGN OF STEEL DOME USING SOFTWARE
}

\author{
Anuj Chandiwala \\ Assistant Professor, Civil Engineering Department, Chhotubhai Gopalbhai Patel Institute of Technology, Gujarat, India
}

\begin{abstract}
In the recent years, there have been an increasing number of structures using steel domes as one of the most efficient shapes in the world. It covers the maximum volume with the minimum larger volumes with no interrupting columns in the middle with an efficient shapes would be more efficient and economic. Dome roofs are the lightest structure to cover circular shape. Dome can be used when the internal pressure is higher; do not have problems with mounting of an internal floating roof. Supplementary foundations are not necessary for dome roofs. In other words always when it is possible the dome roofs are recommended. In this research paper the analysis of steel dome is examined by the use of computer software STAAD.Pro. For the analysis different diameter of the steel tube member and height of steel.
\end{abstract}

Keywords: STAAD.Pro, Dome, Wind Load, Analysis, Diameter of Dome

\section{INTRODUCTION}

A dome is an element of architecture that resembles the hollow upper half of a sphere. Dome structures made of various materials have a long architectural lineage extending into prehistory. Corbel domes and true domes have been found in the ancient Middle East in modest buildings and tombs. The construction of the first technically advanced true domes began in the Roman Architectural Revolution, when they were frequently used by the Romans to shape large interior spaces of temples and public buildings, such as the Pantheon. This tradition continued unabated after the adoption of Christianity in the Byzantine (East Roman) religious and secular architecture, culminating in the revolutionary pendentive dome of the 6th-century church Hagia Sophia. Squinches, the technique of making a transition from a square shaped room to a circular dome, were most likely invented by the ancient Persians. The Sassanid Empire initiated the construction of the first large-scale domes in Persia, with such royal buildings as the Palace of Ardashir, Sarvestan and Ghal'eh Dokhtar. With the Muslim conquest of Greek-Roman Syria, the Byzantine architectural style became a major influence on Muslim societies. Indeed the use of domes as a feature of Islamic architecture has gotten its roots from Roman Greater-Syria (see Dome of the Rock). An original tradition of using multiple domes was developed in the church architecture in Russia, which had adopted Orthodox Christianity from Byzantium. Russian domes are often gilded or brightly painted, and typically have a carcass and an outer shell made of wood or metal. The onion dome became another distinctive feature in the Russian architecture, often in combination with the tented roof. Construction of domes in the Muslim world reached its peak during the 16 th -18 th centuries, when the Ottoman, Safavid and Mughal Empires, ruling an area of the World compromising North Africa, the Middle East and South- and Central Asia, applied lofty domes to their religious buildings to create a sense of heavenly transcendence. The Sultan Ahmed Mosque, the Shah Mosque and the Badshahi Mosque are primary examples of this style of architecture. Many domes built are still in use. According to the Buckminster Fuller Institute, the world's largest domes are bellow:

(1) Fukuoka Dome: Fukuoka, Japan, 710 ft (216 m)

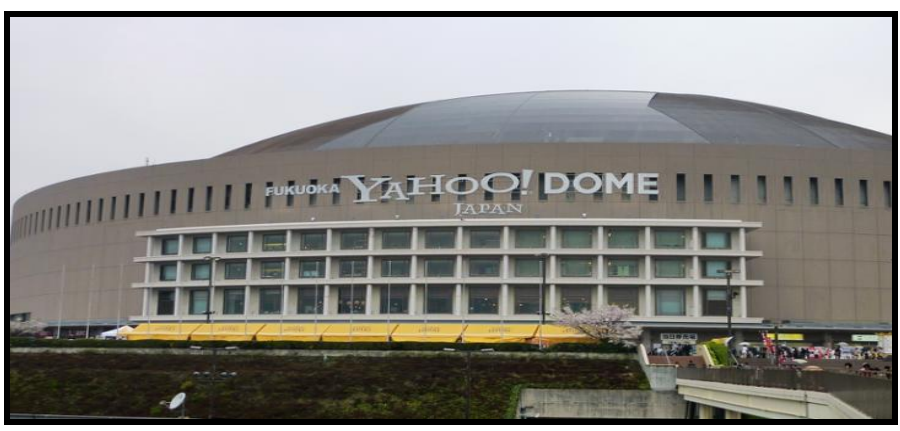

Fig -1: Fukuoka Dome

(2) Nagoya Dome: Nagoya, Japan, 614 ft (187 m)

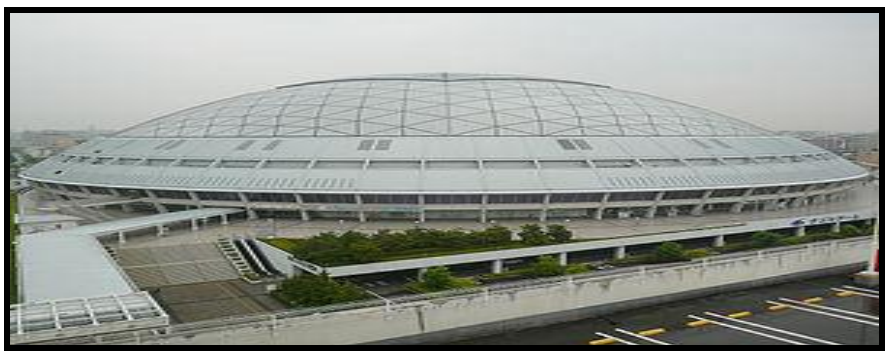

Fig -2: Nagoya Dome 
(3) Walkup Sky dome: Northern Arizona University. Flagstaff, Arizona, USA, $502 \mathrm{ft}(153 \mathrm{~m})$

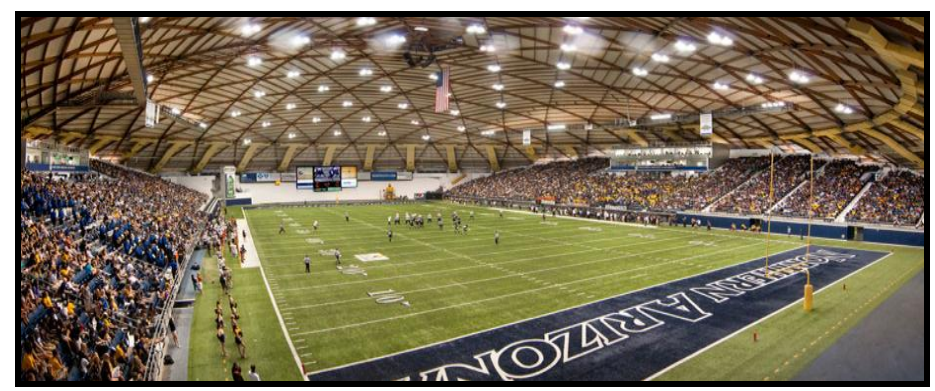

Fig -3: Walkup Sky dome

(4) Formosa Plastics Storage Facility: Mai Liao, Taiwan, 402 $\mathrm{ft}(122 \mathrm{~m})$

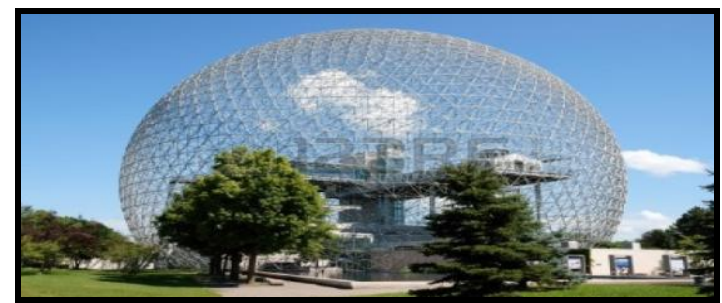

Fig- 4: Formosa Plastics Storage Facility

In structural design, account shall be taken of the dead, imposed and wind loads and forces such as those caused by earthquake, and effects due to shrinkage, creep, temperature, etc, where applicable. There are different types of loads acting on the dome such as Dead Load (DL),Live load (LL) ,Earthquake Load (EQ), Snow Load, Wind Load (WL) and other loads.

\section{DIMENSIONAL ANALYSIS}

In the analysis of the problem of steel dome the variables considered were Diameter, (Figure 5).

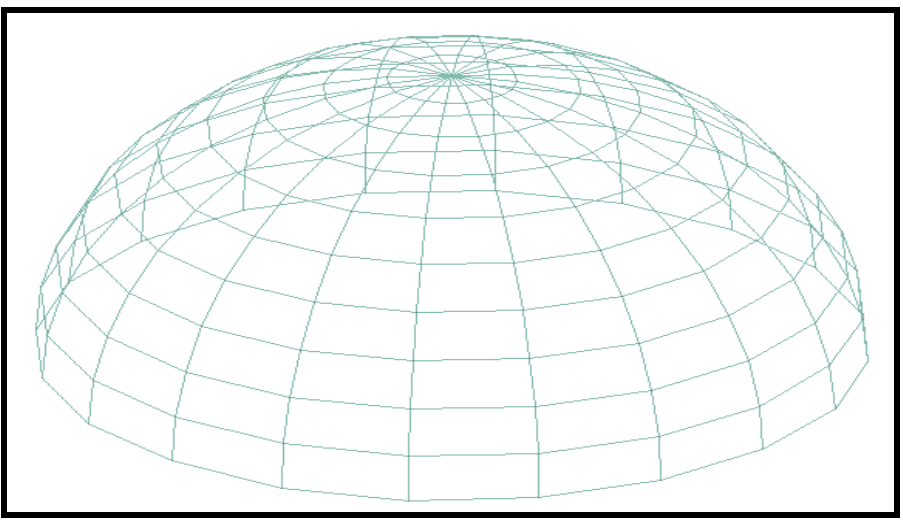

Fig-5: Definition sketch showing the geometry of Dome

\section{MATERIALS AND METHODS}

For the analysis of the dome researcher use steel tube

\subsection{Geometry}

The diameter of dome was used as 20,25,30,35, 40 and 45 $\mathrm{m}$. Size of the tube sections was used as per the diameter of $20,25,30,35,40,45$ as horizontal section $0.20,0.15,0.18$, $0.20,0.23,0.25 \mathrm{~m}$ and for vertical section $0.15,0.14,0.15$, $0.18,0.20,0.23$ respectively. Plate having thickness is $0.008 \mathrm{~m}$

\subsection{Define Load to following process}

The loadings were calculated partially manually and rest was generated using STAAD.Pro load generator. The loading cases were categorized as: Self-weight, Dead load from slab, Live load, Wind load.

3.2.1 Self-weight: The self weight of the structure can be generated by STAAD.Pro itself with the self weight command in the load case column.

3.2.2 Dead load: Dead load can also be generated by STAAD.Pro by specifying the plate thickness and the load on the floor per sq $\mathrm{m}$. Calculation of the load per sq $\mathrm{m}$ was done considering the weight of horizontal beam, weight of vertical column, weight of steel plate.

3.3.3 Live Load: The live loads were generated in a similar manner as done in the earlier case for dead load in each floor. This may be done from the member load button from the load case column. Live load on the dome structure is shown in the figure 6 .

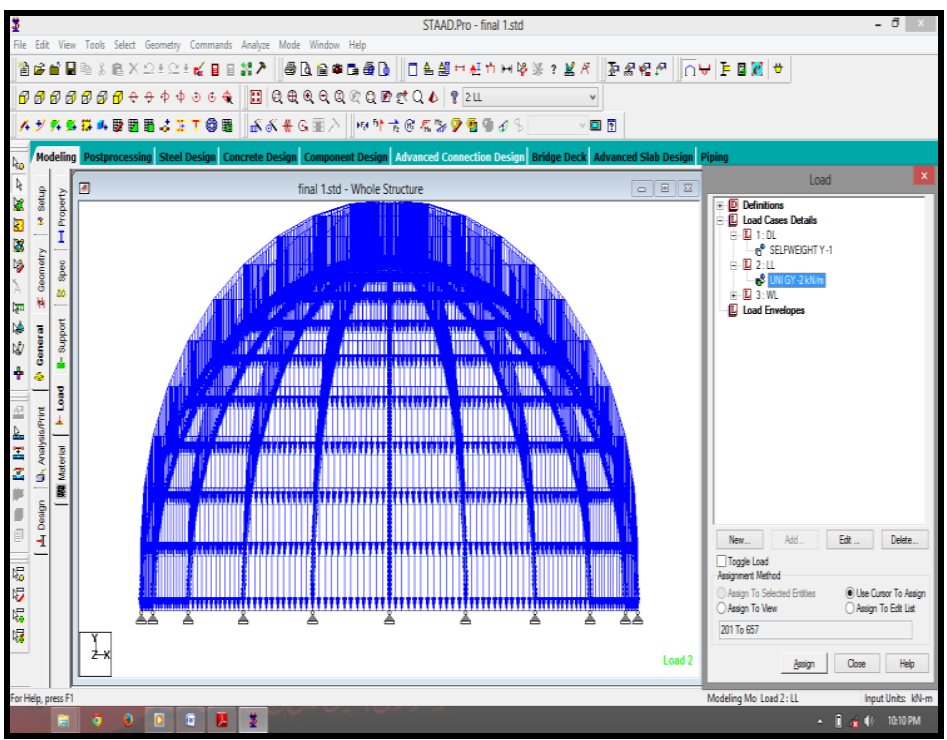

Fig-6: Live load on Dome structure 
3.3.4 Wind load: The wind load values were generated by the software itself in accordance with IS 875. Under the define load command section, in the wind load category, the definition of wind load was supplied. The wind intensities at various heights were calculated manually and feed to the software. Based on those values it generates the wind load at different floors. The design wind speed and wind pressure based on the height of structure is given in the table 1 . Direction of wind load shown in the figure 7 and Figure 8 shows the 3D view of steel dome with beam.

Table -1: Design Wind speed and wind pressure based on height of structures

\begin{tabular}{|l|l|l|}
\hline $\begin{array}{l}\text { Height } \\
{[\mathrm{h}]}\end{array}$ & Design wind speed [Vz] & $\begin{array}{l}\text { Design wind pressure } \\
{[\mathrm{Pz}]}\end{array}$ \\
\hline $\begin{array}{l}\mathrm{Up} \text { to } \\
10 \mathrm{~m}\end{array}$ & $36.379 \mathrm{~m} / \mathrm{s}$ & $0.793 \mathrm{KN} / \mathrm{sq} \mathrm{m}$ \\
\hline $15 \mathrm{~m}$ & $38.85 \mathrm{~m} / \mathrm{s}$ & $0.905 \mathrm{KN} / \mathrm{sq} \mathrm{m}$ \\
\hline $20 \mathrm{~m}$ & $40.51 \mathrm{~m} / \mathrm{s}$ & $0.984 \mathrm{KN} / \mathrm{sq} \mathrm{m}$ \\
\hline $30 \mathrm{~m}$ & $42.58 \mathrm{~m} / \mathrm{s}$ & $1.087 \mathrm{KN} / \mathrm{sq} \mathrm{m}$ \\
\hline
\end{tabular}

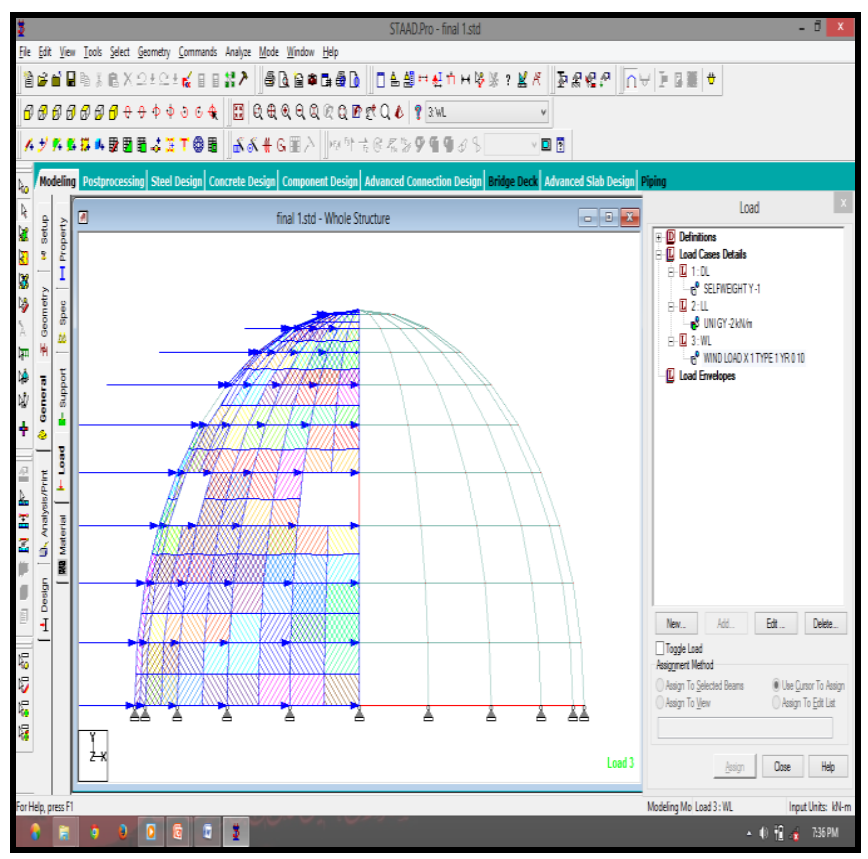

Fig-7: Direction of wind load on structure

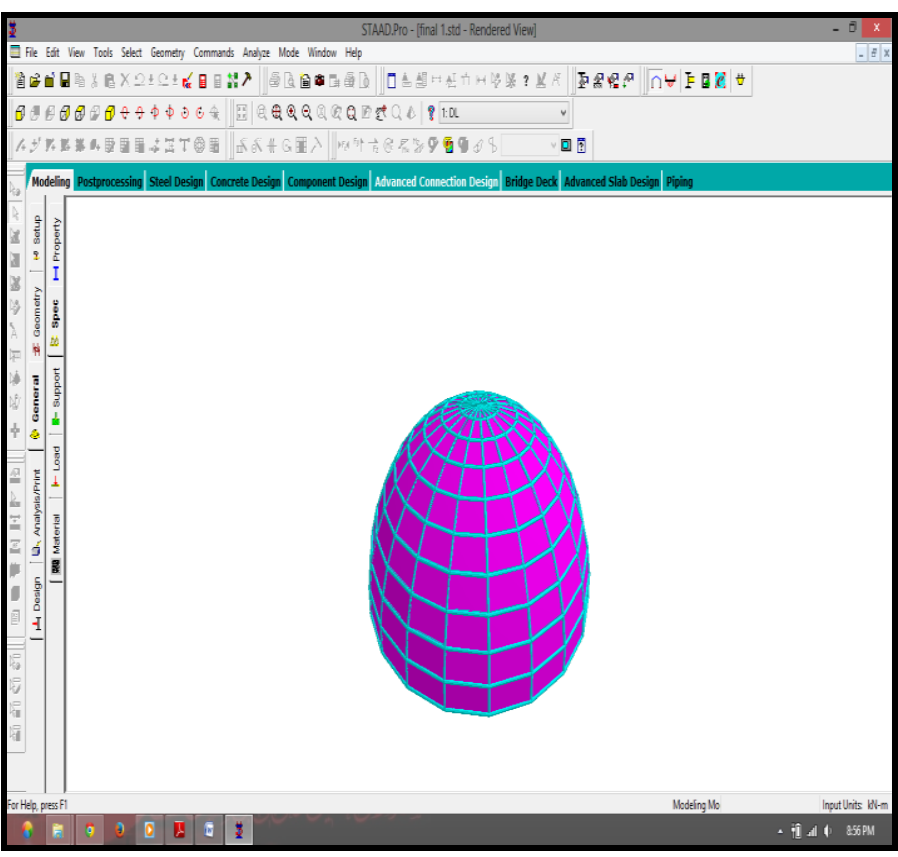

Fig- 8: 3D view of steel dome with beam.

\section{DESIGN RESULTS}

For the sample analysis and design results have been shown below for beam number 344 of steel dome:

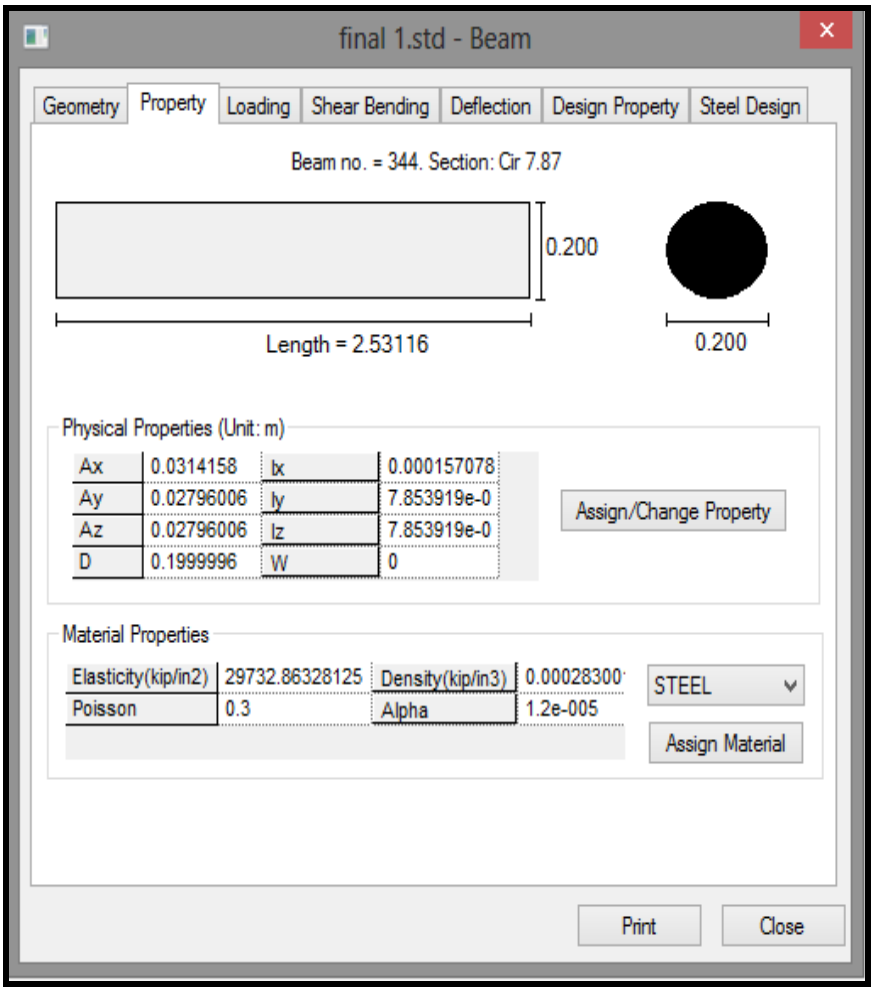

Fig-9: Section property of Beam no. 344. 


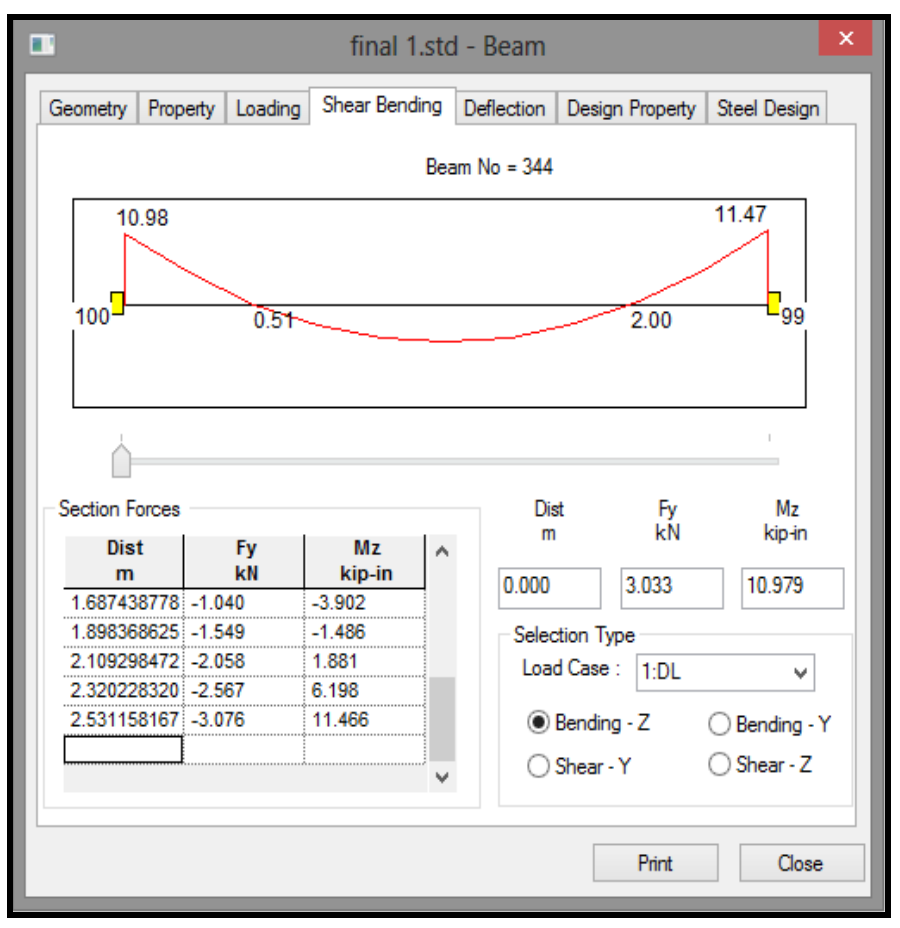

Fig-10: Shear bending diagram of beam 344

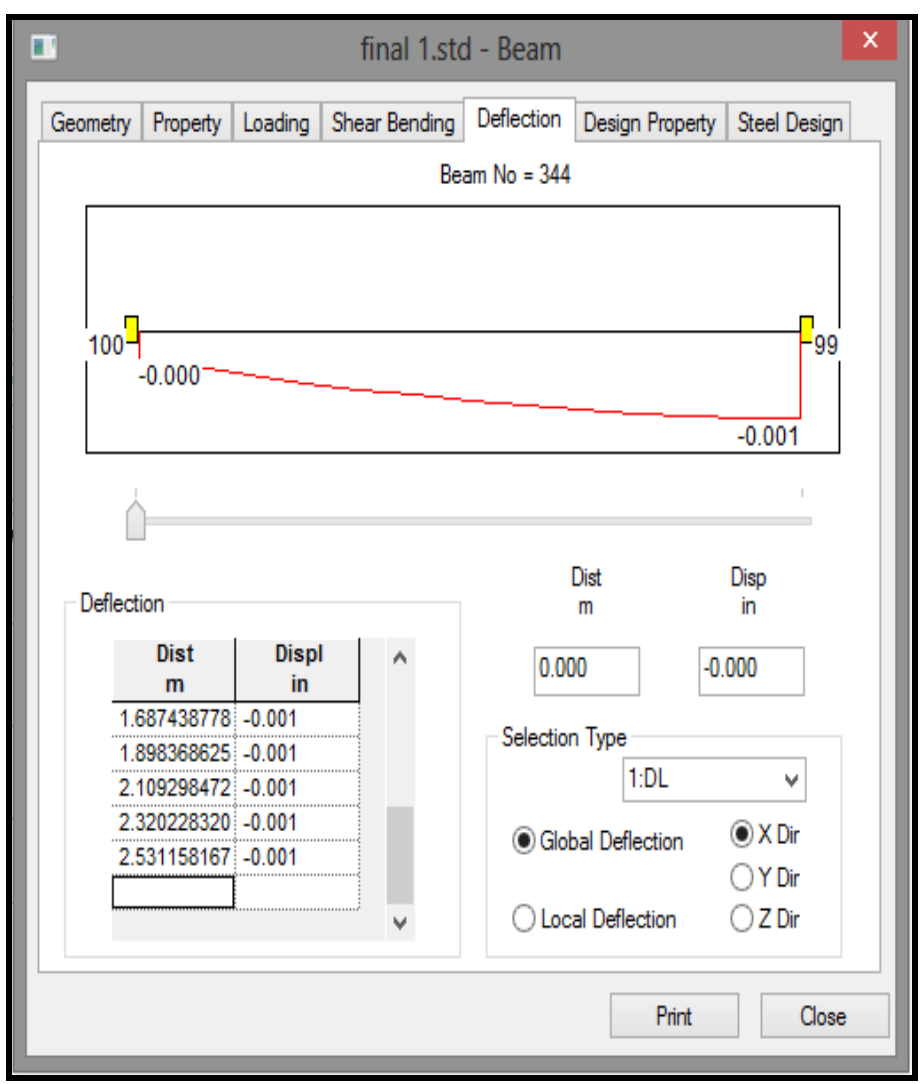

Fig-11: Deflection diagram

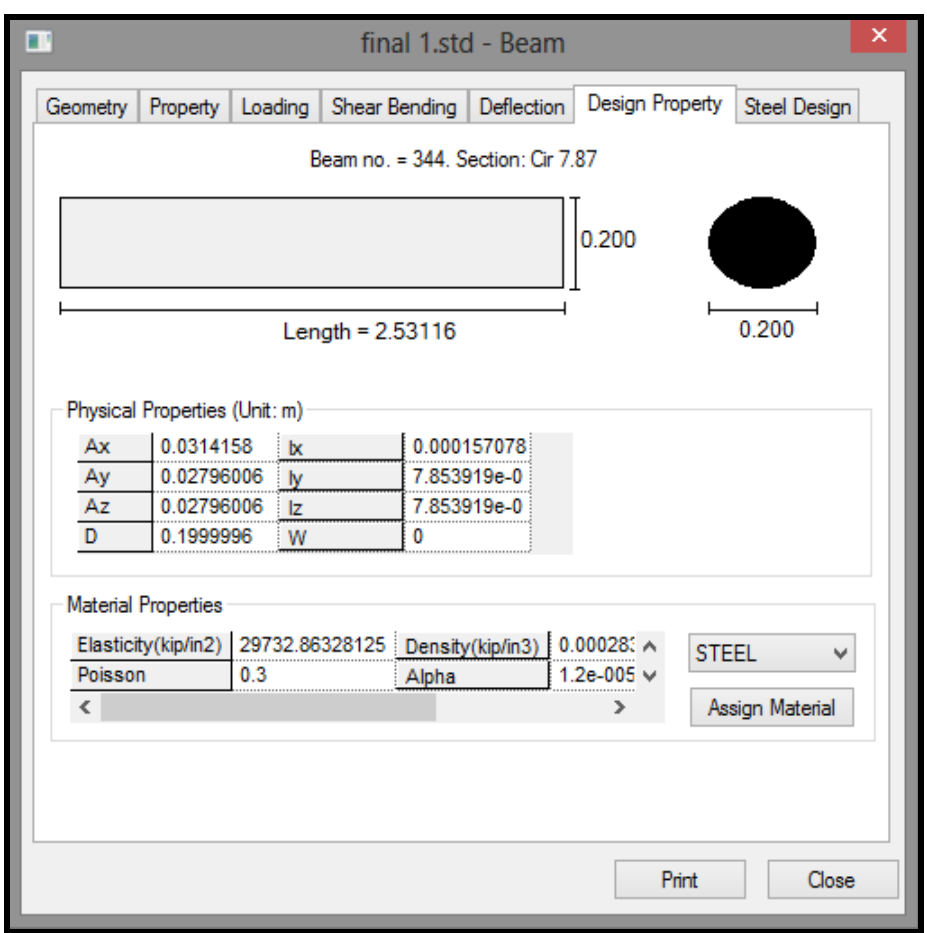

Fig-12: Design Property

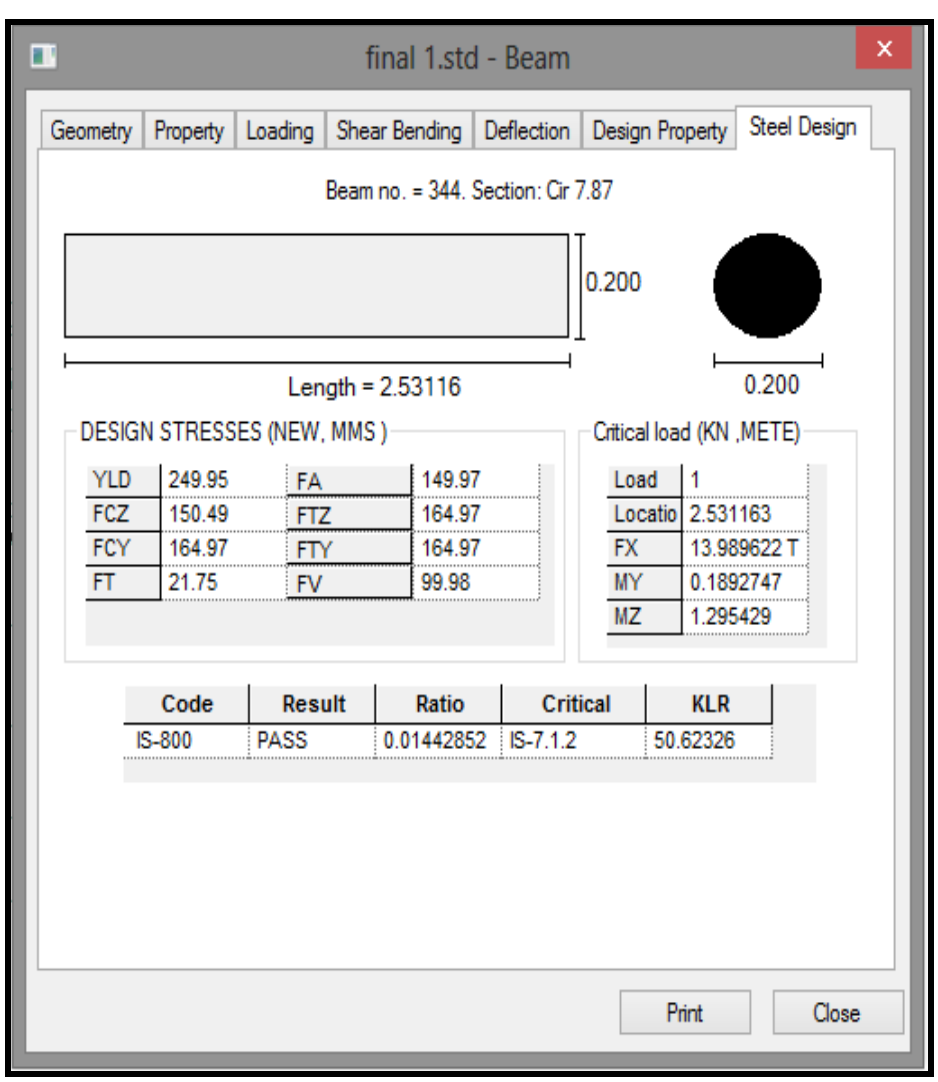

Fig-13: Steel Design 


\section{CONCLUSIONS}

For steel dome take various types of steel section used and compare with how many steel quantities take off to construct steel dome. A various Parameter compare show in following table 2 .

Table- 2: Comparison

\begin{tabular}{|l|l|l|l|l|l|l|}
\hline $\begin{array}{l}\text { Diamete } \\
\text { r of } \\
\text { norizon }\end{array}$ & 0.20 & 25 & 30 & 35 & 40 & 45 \\
$\begin{array}{l}\text { Horizon } \\
\text { tal } \\
\text { Section }\end{array}$ & 0.15 & 0.18 & 0.20 & 0.23 & 0.25 \\
\hline $\begin{array}{l}\text { Vertical } \\
\text { Section } \\
\text { (m) }\end{array}$ & 0.15 & 0.14 & 0.15 & 0.18 & 0.20 & 0.23 \\
\hline $\begin{array}{l}\text { Length } \\
\text { of Steel } \\
\text { (m) }\end{array}$ & 866.50 & 321.52 & 414.41 & 412.79 & 1831.76 & 543.30 \\
\hline $\begin{array}{l}\text { Total } \\
\text { volume } \\
\text { of steel } \\
\text { section } \\
(m 3)\end{array}$ & 22.63 & 4.82 & 9.27 & 12.0 & 69.16 & 24.12 \\
\hline $\begin{array}{l}\text { Steel } \\
\text { take off } \\
(\mathrm{kN})\end{array}$ & 1738.267 & 370.138 & 711.94 & 921.45 & 3312.827 & \\
\hline
\end{tabular}

STAAD PRO has the capability to calculate the any steel structure section. The program contains a number of parameters which are designed as per IS: 800:2007.

\section{Horizontal Steel section Design Output:}

The default design output of the beam contains flexural and steel provided along the length of the beam.

\section{Vertical steel section Design:}

Columns are designed for axial forces and biaxial moments at the ends. All active load cases are tested to calculate steel section. The loading which yield maximum steel section is called the critical load. Vertical steel section design is done for circular. Circular steel columns are designed with steel distributed on each side equally for the sections under biaxial moments and with steel distributed equally in two faces for sections under uni-axial moment. All major criteria for selecting longitudinal and transverse steel as stipulated by IS: 800:2007 have been taken care of in the column design of STAAD PRO.

\section{REFERENCES}

[1]. Xingfei Yuan, Lianmeng Chen, Shilin Dong "Prestress design of cable domes with new forms" Space Structures Research Center, Zhejiang University, Hangzhou 310027 , China.

[2]. Prof. Lei Guo, Jinjiang Zhang, Bo Zhang "Structures, kinematics, thermochronology and tectonic evolution of the Ramba gneiss dome in the northern Himalaya" The Key Laboratory of Orogenic Belts and Crustal Evolution, Ministry of Education, China School of Earth and Space Sciences, Peking University, Beijing 100871, China.

[3]. Hoang ChiTran a, HyoSeonPark b, JaehongLee a,n "A unique feasible mode of prestress design for cable domes" a Department of Architectural Engineering, Sejong University, 98 Kunja Dong, KwangjinKu,Seoul 143-747,Republicof Korea.

[4]. Wenjiang Kang a, Zhihua Chen a, Heung-Fai Lam b,*, Chenran Zuo "Analysis and design of the general and outmost-ring stiffened suspen-dome structures" a Department of Civil Engineering, Tianjin University, Tianjin, China b Department of Building and Construction, City University of Hong Kong, Hong Kong.

[5]. Shiro Katoa,_, Tetsuo Yamashitab, Shoji Nakazawaa, Yun-beom Kima, Atsushi Fujibayashia "Analysis based evaluation for buckling loads of two-way elliptic paraboloidal single layer lattice dome" a Toyohashi University of Technology, Tempaku, Toyohashi 441-8580, Japan.

[6]. Z. Cui *, G. Moltschaniwskyj, D. Bhattacharyya. "Buckling and large deformation behaviour of composite domes compressed between rigid platens" Centre for Advanced Composite Materials, The University of Auckland, New Zealand Available online 9 June 2004.

[7]. J. B"achut "Buckling of multilayered metal domes" The University of Liverpool, Mechanical Engineering, Liverpool L69 3GH, UK.

[8]. Zhi-Wei Yu a,n, Xu-DongZhi a, FengFan a, ChenLu b "Effect of substructures upon failure behavior of steel reticulated domes subjected to the severe earthquake" Department of Civil Engineering, Harbin Institute of Technology, Post Code 150090, Harbin, PR China.

\section{BIOGRAPHIES}

Working as an assistant professor in Technology, in civil Engineering Department

\section{Research Interests:}

Earthquake Resistant Structural Analysis \& Design using computer added software (STAAD PRO, MIDAS, STRUDS, SAP 2000, and MIDAS GTS.

Pile Raft Foundation.

Structural Analysis of Shear wall using structural software 